\title{
3D-printed coded apertures for x-ray backscatter radiography
}

\author{
André A. M. Muñoz ${ }^{\mathrm{a}}$, Anna Vella ${ }^{\mathrm{a}}$, Matthew J. F. Healy ${ }^{\mathrm{a}}$, David W. Lane ${ }^{\mathrm{a}}$, Ian Jupp ${ }^{\mathrm{b}}$, and \\ David Lockley ${ }^{\mathrm{b}}$ \\ ${ }^{a}$ Cranfield Forensic Institute, Cranfield University, Defence Academy of the United \\ Kingdom, Shrivenham, SN6 8LA, United Kingdom \\ ${ }^{\mathrm{b}}$ Counter Terrorism \& Security Division, Defence Science and Technology Laboratory, Fort \\ Halstead, TN14 7BP, United Kingdom
}

\begin{abstract}
Many different mask patterns can be used for X-ray backscatter imaging using coded apertures, which can find application in the medical, industrial and security sectors. While some of these patterns may be considered to have a self-supporting structure, this is not the case for some of the most frequently used patterns such as uniformly redundant arrays or any pattern with a high open fraction. This makes mask construction difficult and usually requires a compromise in its design by drilling holes or adopting a no two holes touching version of the original pattern. In this study, this compromise was avoided by 3D printing a support structure that was then filled with a radiopaque material to create the completed mask. The coded masks were manufactured using two different methods, hot cast and cold cast. Hot casting involved casting a bismuth alloy at $80^{\circ} \mathrm{C}$ into the 3D printed acrylonitrile butadiene styrene mould which produced an absorber with density of $8.6 \mathrm{~g} \mathrm{~cm}^{-3}$. Cold casting was undertaken at room temperature, when a tungsten/epoxy composite was cast into a 3D printed polylactic acid mould. The cold cast procedure offered a greater density of around 9.6 to $10 \mathrm{~g} \mathrm{~cm}^{-3}$ and consequently greater X-ray attenuation. It was also found to be much easier to manufacture and more cost effective. A critical review of the manufacturing procedure is presented along with some typical images. In both cases the 3D printing process allowed square apertures to be created avoiding their approximation by circular holes when conventional drilling is used.
\end{abstract}

Keywords: Coded masks, coded apertures, 3D printed, X-ray backscatter, Technon ${ }^{\circledR}$, low cost apertures.

\section{INTRODUCTION}

Coded apertures (CAs) date back to the $1960 \mathrm{~s}^{1,2}$ with imaging applications in far-field X-ray astronomy, ${ }^{2}$ medical imaging ${ }^{3,4}$ and defence and security. ${ }^{5}$ CAs utilise the principle of a pinhole camera, but with multiple apertures to increase throughput whilst retaining the resolution. The imaging process works by radiation passing through the $\mathrm{CA}$ and projecting a shadow of the array pattern onto a detector. Consequently, a scrambled encoded image is formed and the image reconstruction is performed using a mathematical process of correlation with a decoding array. ${ }^{3}$ Due to the nature of an array pattern, a CA usually lacks self supporting qualities, which render them difficult to manufacture. This is more prevalent with CAs containing higher open fractions such as the Uniformly Redundant Arrays. ${ }^{6}$ A no two holes touching $(\mathrm{NTHT})^{7}$ version of an array is commonly adopted for physically constructed CAs. NTHTs create an opaque spacing between each individual element in the array that acts as a support structure. However, noise is inherited into the $\mathrm{CA}$, compromising image quality. In the past, 3D printing and tungsten powder casting have been applied to high density imaging apertures. ${ }^{8}$ This may be considered as an alternative approach to manufacturing CAs, with less of a compromise in image quality.

Further author information: (Send correspondence to André Muñoz)

André Muñoz: E-mail: a.munoz@cranfield.ac.uk 
In the work presented in this paper, a 0.5 open fraction Modified Uniformly Redundant Array (MURA $)^{9}$ was fabricated using 3D printing and tungsten powder casting at room temperature. In addition, experiments were conducted with hot casting a bismuth alloy, investigating the ease of manufacture of each method. The manufacturing procedure is detailed along with presented images from each mask, which for comparison includes those from a standard tungsten alloy NTHT CA.

\section{EXPERIMENTAL METHOD}

Experiments were conducted with a $800 \mathrm{~W} \mathrm{VJT}^{\circledR} \mathrm{X}$-ray source, ${ }^{10}$ which was operated at $100 \mathrm{kV}$ and 5 $\mathrm{mA}$. Images of a radioactive ${ }^{241} \mathrm{Am}$ source and backscattered X-rays from objects were recorded using a Photonic Science ${ }^{\circledR}$ X-ray sensitive iCCD camera. ${ }^{11}$ Both were centred within the detector's field of view (FOV), and placed at a distance of $1 \mathrm{~m}$ from the $\mathrm{CA}$ for the radioactive source and $1.5 \mathrm{~m}$ for the X-ray backscatter objects. The distance from the CA to the focal plane of the detector was set to $111 \mathrm{~mm}$ for X-ray backscattered objects and $141 \mathrm{~mm}$ for the radioactive source. The test objects comprised of a quadrant of three blocks and a cylinder, and a pair of scissors placed in front of a parrafin wax block. Two types of CAs were used for imaging; the 3D printed cold cast 19 MURA and a Wolfmet HA $190^{12}$ tungsten alloy NTHT version. Results from CAs constructed using the hot cast method are not presented in this paper, as benefits from cold casting far out weight those from the hot cast mathod (a critical review will be presented later on). Images presented later in this paper were taken using CAs with $2 \mathrm{~mm}$ thick X-ray attenuating material. In addition, all presented CAs were mosaicked in order to lower the effects of partially coded field of view (PCFOV). ${ }^{3,9,13,14}$ Care was taken during the CA design phase so that the unit pattern was smaller than the detector's active area. As a result, the CA's unit pattern shadow projected a full cycle within the detector's active area.

\subsection{CA construction}

The coordinates of a 19 MURA's open elements were imported as a table driven pattern into the 3D computer aided diagram $(\mathrm{CAD})$ program Solidworks ${ }^{\circledR 15}$ and an array pattern was merged with a plain mould containing a central cavity to complete the CA mould design (see Fig.1).

(a)

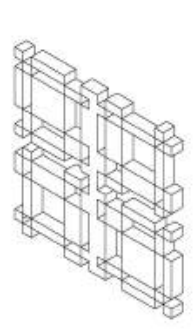

(b)

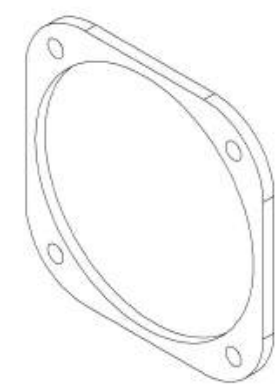

(c)

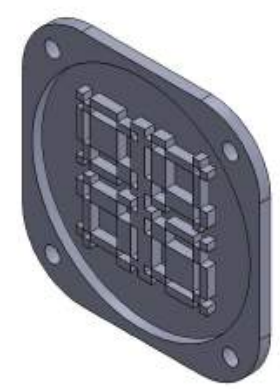

Figure 1: Solidworks ${ }^{\circledR}$ rendering of (a) array pattern (b) plain mould (c) CA mould.

Subsequently, the CA mould was exported as a STereoLithography (STL) file and imported into the 3D printer slicing application CURA ${ }^{\circledR}, 16$ where $3 \mathrm{D}$ prints in both polylactic acid (PLA) and acrylonitrile butadiene styrene (ABS) were made on a Ultimaker 2 Extended ${ }^{\circledR}{ }^{17} 3 \mathrm{D}$ printer (see Table 1 for settings).

\subsection{Cold casting}

The process of cold casting $3 \mathrm{D}$ printed CAs required casting a tungsten-expoxy resin composite (Technon ${ }^{\circledR}$ Poly Kit ${ }^{19}$ ) at room temperature using a PLA CA mould. The Technon ${ }^{\circledR}$ Poly Kit comprised of 100 mesh 
Table 1: Ultimaker 2 Extended ${ }^{\circledR}$ 3D print settings.

\begin{tabular}{|c|c|c|c|}
\hline & & PLA & ABS \\
\hline & PARAMETER & \multicolumn{2}{|c|}{ VALUE } \\
\hline QUALITY & $\begin{array}{l}\text { Layer height } \\
\text { Shell thickness } \\
\text { Initial layer thickness } \\
\text { Enable retraction }\end{array}$ & $\begin{array}{l}0.1 \mathrm{~mm} \\
0.8 \mathrm{~mm} \\
0.3 \mathrm{~mm} \\
\text { Yes }\end{array}$ & $\begin{array}{l}0.1 \mathrm{~mm} \\
0.8 \mathrm{~mm} \\
0.3 \mathrm{~mm} \\
\text { Yes }\end{array}$ \\
\hline SPEED & $\begin{array}{c}\text { Travel speed } \\
\text { Bottom layer speed } \\
\text { Infill speed } \\
\text { Outer shell speed } \\
\text { Inner shell speed }\end{array}$ & $\begin{array}{c}150 \mathrm{~mm} / \mathrm{s} \\
30 \mathrm{~mm} / \mathrm{s} \\
100 \mathrm{~mm} / \mathrm{s} \\
40 \mathrm{~mm} / \mathrm{s} \\
80 \mathrm{~mm} / \mathrm{s}\end{array}$ & $\begin{array}{l}250 \mathrm{~mm} / \mathrm{s} \\
20 \mathrm{~mm} / \mathrm{s} \\
50 \mathrm{~mm} / \mathrm{s} \\
50 \mathrm{~mm} / \mathrm{s} \\
50 \mathrm{~mm} / \mathrm{s}\end{array}$ \\
\hline TEMPERATURE & $\begin{array}{l}\text { Nozzle temperature } \\
\text { Build plate temperature }\end{array}$ & $\begin{array}{c}210-220^{\circ} \mathrm{C} \\
60^{\circ} \mathrm{C}\end{array}$ & $\begin{array}{c}240-260^{\circ} \mathrm{C} \\
100^{\circ} \mathrm{C}\end{array}$ \\
\hline SUPPORT & $\begin{array}{l}\text { Brim } \\
\text { Build plate }\end{array}$ & $\begin{array}{c}\text { No } \\
\text { Glue stick }\end{array}$ & $\begin{array}{c}\text { Yes } \\
\text { Kapton }{ }^{\circledR} 18\end{array}$ \\
\hline
\end{tabular}

tungsten powder $(149 \mu \mathrm{m}$ maximum particle size $)$ and a two part epoxy resin $\left(E_{P}\right)$. The Technon ${ }^{\circledR}$ mixture was mixed by hand for $25-30$ seconds and poured into the CA mould. Densities of the cured mixture $\left(\rho_{M}\right)$ varied from $9.6-10.6 \mathrm{~g} \mathrm{~cm}^{-3}$ calculated using Eq.1 and 2, where $S$ is the weight ratio of each element or compound in a $100 \mathrm{~g}$ sample. Other variables include density $\left(\rho_{i}\right)$ and volume $\left(V_{i}\right)$, where $i$ represents each constituent element/compound . $E_{P}$ was assumed to have a density of $\rho_{M}, 1.17 \mathrm{~g} \mathrm{~cm}^{-3}$. The cast was cured for 24 hours at room temperature and the CA was polished to remove excess mixture (see Fig.2 for examples).

$$
\begin{gathered}
V_{i}=\frac{S}{\rho} \\
\rho_{M}=\frac{1}{\sum_{i} V_{i}} 100 \mathrm{~g}
\end{gathered}
$$

\subsection{Hot casting}

A bismuth alloy (Bi 57, Sn 26, In 17)wt\% and 3D printed ABS CA mould was used to hot cast CAs. The bismuth alloy was chosen because of its relatively high density of $8.6 \mathrm{~g} \mathrm{~cm}^{-3}$ and eutectic temperature of $80^{\circ} \mathrm{C}$. The melting process began with $\mathrm{Bi}$, as it contained the highest melting point of all elements within the alloy. All remaining elements were added to the liquid metal, which was cooled to $90-100^{\circ} \mathrm{C}$ and mixed to form a liquid alloy. Unlike PLA which has a glass transition $\left(T_{g}\right)$ of $60^{\circ} \mathrm{C}, T_{g}$ of $\mathrm{ABS}$ can withstand higher 
(a)

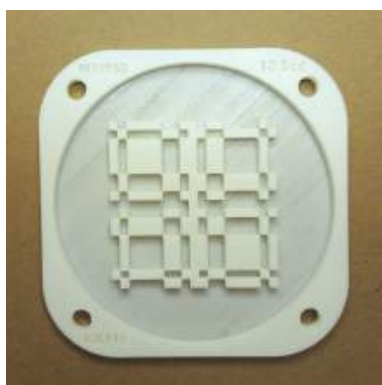

(d)

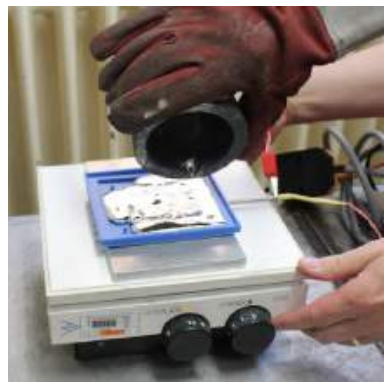

(b)

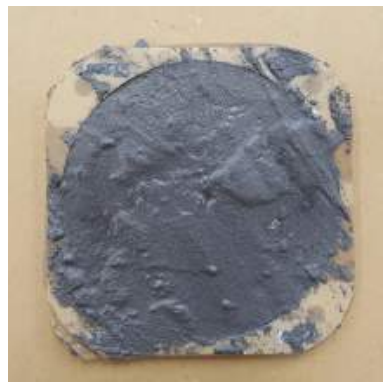

(e)

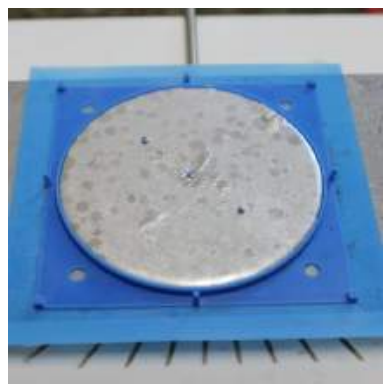

(c)

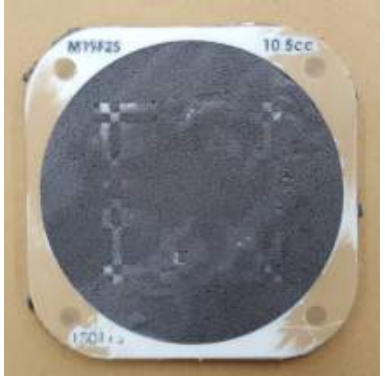

(f)

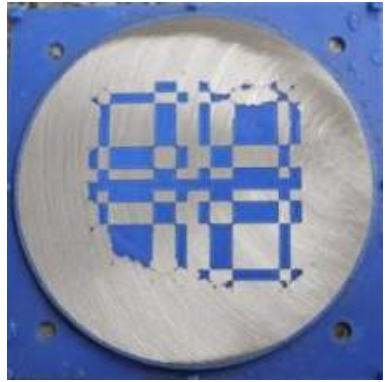

Figure 2: (a) 3D printed PLA CA mould (b) cast with Technon ${ }^{\circledR}$ then (c) partly polished. (d) Shows the hot casting process at $90-100^{\circ} \mathrm{C}$ (e) which was cooled and (f) partly polished to reveal the CA pattern.

temperatures of up to $105^{\circ} \mathrm{C}$. Consequently, this rendered ABS the best candidate for hot casting. The bismuth alloy was poured into the $\mathrm{CA}$ mould at $90-100^{\circ} \mathrm{C}$, allowed to cool for $3-4$ hours and then polished to reveal its array pattern (see Fig.2).

\subsection{Decoding process}

The image encoding process is described in Eq.3, where $D$ is the encoded image recorded by the camera, and where the object $O$ is correlated with the $\mathrm{CA}$ array pattern $A, \mathrm{~N}$ is the addition of some noise term and $\otimes$ is the correlation operator. Each encoded image had the mosaic cropped and removed so that its size only matched the unit pattern of the CA. Cropping the mosaic out from $D$ was imperitive for eliminating unwanted artefacts that may be introduced by the correlation process. ${ }^{13}$

$$
D=(O \otimes A)+\mathrm{N}
$$

$O$ is obtained by decoding $D$ using a decoding array $G$ such that a Dirac delta function $(\delta$ ) is produced (see Eq.4).

$$
A \otimes G=\delta
$$

Due to near field magnification $\left(N_{m}\right), G$ was scaled using Eq.5, where $a$ is the distance between the object and $\mathrm{CA}$, and $b$ is the distance between the CA and the detector's focal plane. Consequently, this ensured that the unit pattern from both $D$ and $G$ were equal in size.

$$
N_{m}=\frac{a+b}{b}
$$


All reconstructed images $R$ were calculated using a fast normalized correlation function (see E.q.6) within MATLAB $^{\odot},{ }^{20,21} \bar{D}$ and $\bar{G}$ are the mean values of $D$ and $G$.

$$
R(u, v)=\frac{\sum_{x, y}\left[G(x, y)-\bar{G}_{u, v}\right][D(x-u, y-v)-\bar{D}]}{\sqrt{\sum_{x, y}\left[G(x, y)-\bar{G}_{u, v}\right]^{2} \sum_{x, y}[D(x-u, y-v)-\bar{D}]^{2}}}
$$

For the cross correlation process to occur $G$ or $D$ had to be larger than the other, with the unit pattern remaining the same size. $A$ and $G$ contained the same array pattern, however, with the conditions in Eq.7 being applied to $G$ 's open and closed elements. ${ }^{9}$ As the MURA was used for taking exposures, the decoding array was subject to slight modification of $G_{1,1}=1$, if $A_{1,1}=0$ as stated, by Fenimore \& Gottesman. ${ }^{9}$ Because the MURA in this experiment was centred through circular shifting the condition was applied to the central element.

$$
G_{i, j}=\left\{\begin{array}{cc}
1 & \text { if } A_{i, j}=1 \\
\eta & \text { if } A_{i, j}=0
\end{array}\right\} \quad \text { where, } \eta=-\frac{\rho}{1-\rho}
$$

Each image of the radioactive source comprised of a single $300 \mathrm{~s}$ exposure. All reconstructed X-ray backscatter images were formed from two $5 \mathrm{~s}$ exposures. The initial exposure was captured with the CA in its correct orientation and was added to another with the CA rotated 90 degrees. This removed artefacts travelling with the CA's rotation. ${ }^{22}$ All images presented in this paper were not subject to further image enhancement and were automatically reconstructed in MATLAB ${ }^{\odot} .20$ The total image reconstruction time was less than 2 s on a standard personal computer. The process included all scaling, cropping, correlation and summations.

\section{RESULTS}

Final constructed 3D printed CAs made with the hot and cold casing methods are presented in Fig.3. CAs in Fig.3a and $\mathrm{b}$ were fabricated for an earlier version of the imaging system and are presented for demonstration purposes. The CA in Fig.3c was mosaicked ${ }^{3,9,13,14}$ and manufactured for the current imaging system. 3D printed CA exposures presented within this paper were taken using the CA in Fig.3c.

(a)

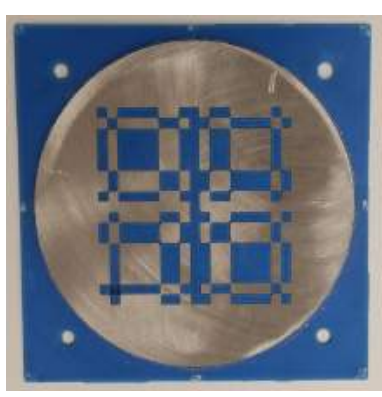

(b)

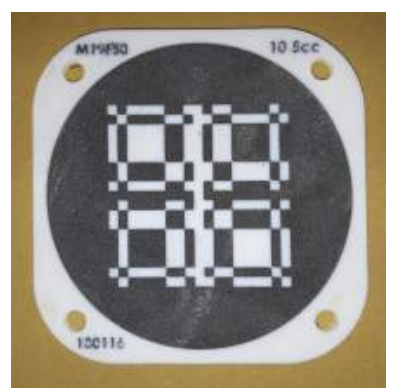

(c)

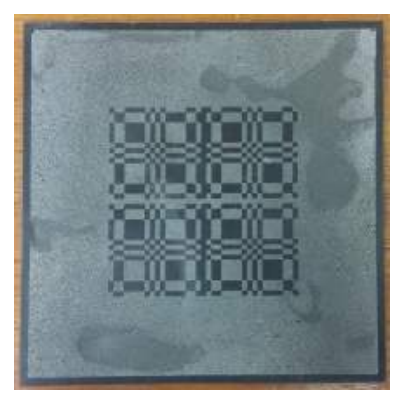

Figure 3: 3D printed CAs. (a) hot cast with a 19 MURA unit pattern (Note, the missing metallic element in the lower left corner), (b) cold cast containing a 19 MURA unit pattern, (c) 19 MURA mosaic constructed by the cold cast method. 


\subsection{Theoretical PSF and CA exposures}

The theoretical point spread function (PSF) of the 19 MURA and its NTHT variant were calculated (see E.q.6) and are predicted in Fig.4 and 5 for comparison with experimental CA exposures of the ${ }^{241}$ Am source (see Fig.6). In addition, X-ray backscatter images of the test objects were taken using both the 3D printed and tungsten alloy NTHT CAs (see Fig.7 and 8). The size of each image varied with the unit pattern size and as the NTHTs unit pattern was larger the image and detected area was greater. Signal to noise ratio (SNR) of the 3D printed CA and tungsten alloy NTHT were calculated using ImageJ ${ }^{\circledR 23}$ for each image of the ${ }^{241} \mathrm{Am}$ source. This involved cropping the mean signal in the image by eye and dividing it by the standard deviation of the background. The background signal consisted of a plateau and side-lobes that are not apparent in the images due to their low contrast. The results revealed SNR values of 37.3 for the 3D printed CA and 32.9 for its tungsten NTHT version. Also, the full width at half maximum (FWHM) of the ${ }^{241} \mathrm{Am}$ source image was found with an automated process using MATLAB ${ }^{\complement}$. FWHM for both CAs were 30 and 36 pixels for the 3D printed CA and tungsten NTHT version.

(a)

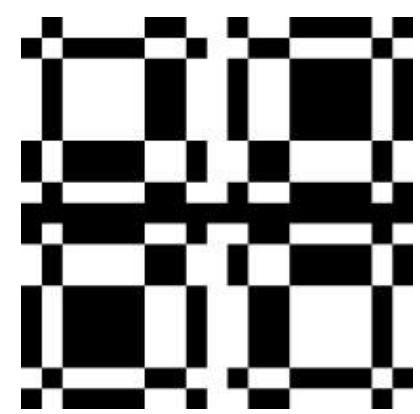

(b)

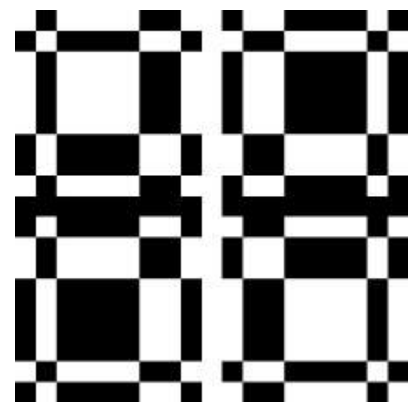

(c)

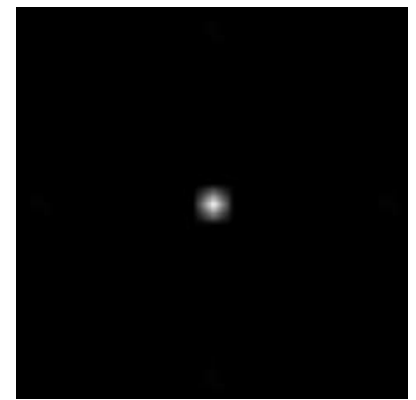

Figure 4: Theoretical PSF 19 MURA. (a) CA pattern with 1 and 0 for open and closed elements which was correlated with the (b) decoding array of 1 and -1 for its open and closed elements. (c) Calculated PSF .

(a)

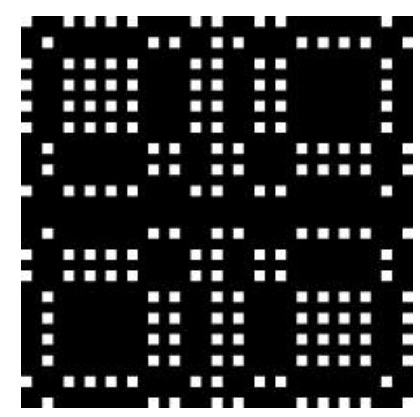

(b)

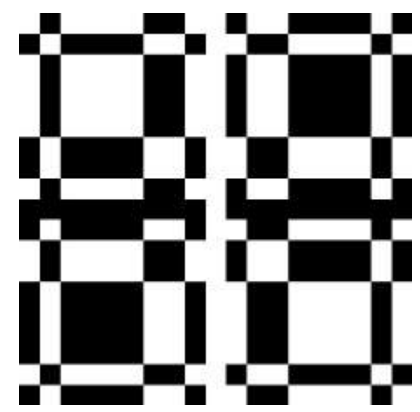

(c)

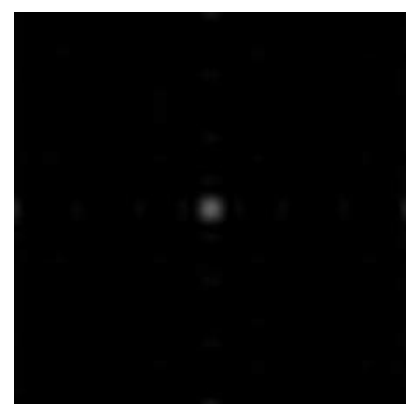

Figure 5: Theoretical PSF of the NTHT version of 19 MURA. (a) NTHT pattern containing 1 and 0 for its open and closed elements which was then correlated with the (b) decoding array of 1 and -1 for its open and closed elements. (c) Calculated PSF. 
(a)

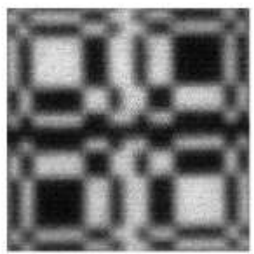

(d)

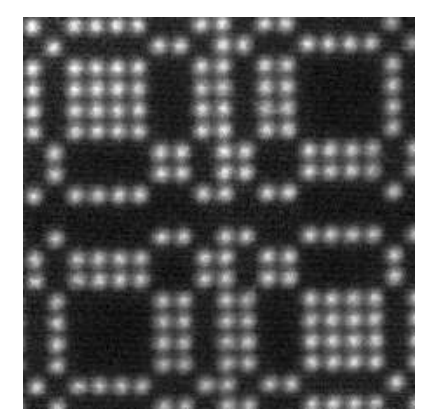

(b)

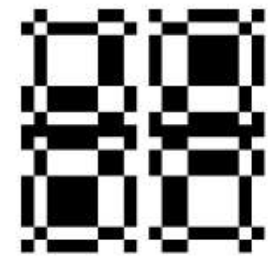

(e)

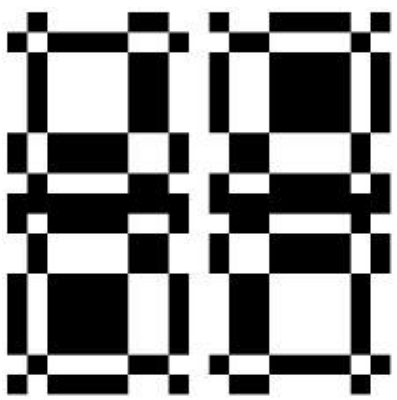

(c)

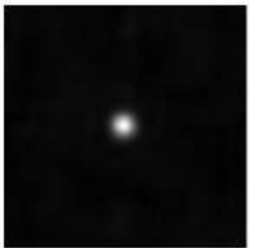

(f)

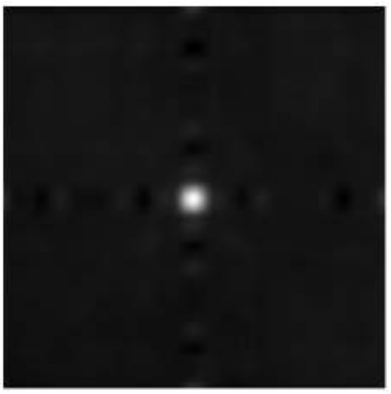

Figure 6: Experimental 3D printed CA and tungsten alloy NTHT exposure of an (a)(d) ${ }^{241}$ Am radioactive source exposure correlated with the (b)(e) decoding array of 1 and -1 for the open and closed elements. (c)(f)Decoded images.

(a)

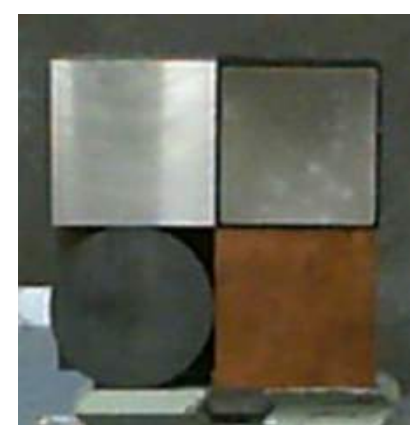

(b)

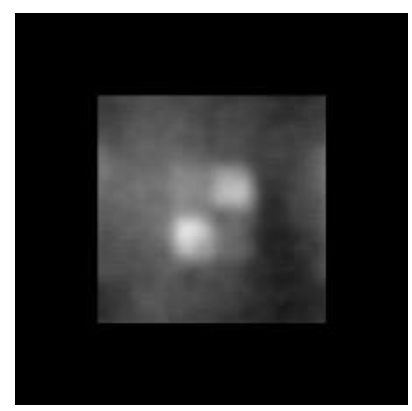

(c)

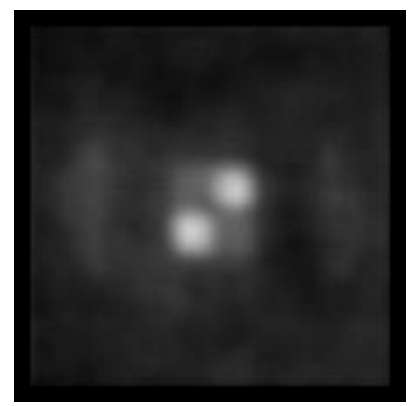

Figure 7: (a) quadrant of a $10 \mathrm{~cm}$ diameter cylinder and three $10 \times 10 \times 5 \mathrm{~cm}$ solid blocks constructed from aluminium in the top left, top right; paraffin wax in a PLA mould, bottom left; PVC and bottom right; copper. (b) Exposures taken with the 3D printed CA and its (c) tungsten alloy NTHT version.

\subsection{Density and X-ray transmission}

An Accupyc 1330 pycnometer $^{24}$ was used to analyse the density of the CAs attenuating material which was compared to the calculated value (see Table 2). The pycnometer measures the change in gas volume of an empty chamber, compared to one with the sample contained within it and then calculates the sample's 
(a)

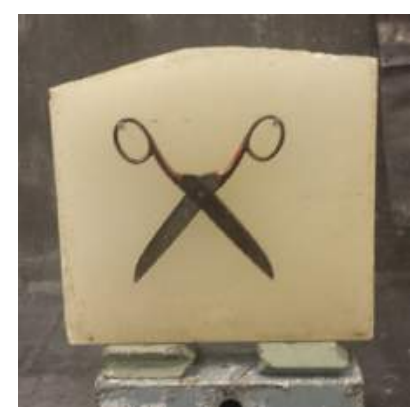

(b)

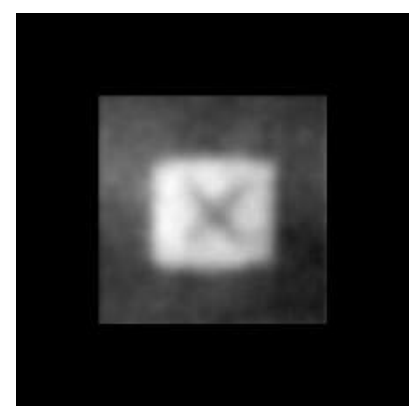

(c)

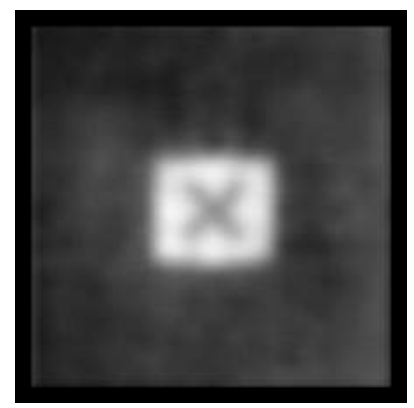

Figure 8: (a) shows a pair of scissors in front of a wax block. (b) Exposures taken with the 3D printed CA and its (c) tungsten alloy NTHT version.

density using it's weight.

Table 2: Calculated and confirmed densities for the CAs attenuating material. The uncertainty of the confirmed experiential density is the standard deviation.

\begin{tabular}{|c|c|c|c|c|}
\hline $\begin{array}{l}\text { ATTENUATING } \\
\text { MATERIAL }\end{array}$ & $\begin{array}{l}\text { Concentration } \\
\text { (wt\%) }\end{array}$ & $\begin{array}{c}\text { CALCULATED } \\
\text { DENSITY } \\
\left(\mathrm{g} \mathrm{cm}^{-3}\right)\end{array}$ & $\begin{array}{c}\text { CONFIRMED } \\
\text { DENSITY } \\
\left(\mathrm{g} \mathrm{cm}^{-3}\right)\end{array}$ & $\begin{array}{l}\text { UNCERTAINTY } \\
\quad\left(\mathrm{g} \mathrm{cm}^{-3}\right)\end{array}$ \\
\hline 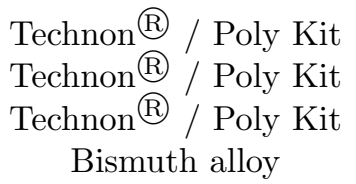 & $\begin{array}{c}93.5 \mathrm{~W}, 6.5 \mathrm{E}_{\mathrm{P}} \\
94.6 \mathrm{~W}, 5.4 \mathrm{E}_{\mathrm{P}} \\
94.9 \mathrm{~W}, 5.1 \mathrm{E}_{\mathrm{P}} \\
\text { Bi } 57, \text { Sn } 26, \text { In } 17\end{array}$ & $\begin{array}{c}9.6 \\
10.5 \\
10.8 \\
8.5\end{array}$ & $\begin{array}{c}9.57 \\
10.63 \\
10.09 \\
8.61\end{array}$ & $\begin{array}{l} \pm 0.02 \\
\pm 0.06 \\
\pm 0.08 \\
\pm 0.02\end{array}$ \\
\hline
\end{tabular}

\subsection{Material analysis}

The 100 mesh tungsten powder used in the Technon ${ }^{\circledR}$ mixture was analysed using a HITACHI SU5000 Scanning Electron Microscope (SEM). ${ }^{25}$ Data was collected in three randomly selected regions of the sample which show the tungsten particles relative shape and size. A section of each hot and cold CAs cast was sampled and set in resin to analyse its integrity. The cured Technon ${ }^{\circledR}$ mixture disclosed voids which indicated the presence of air pockets in the cast (see Fig.9). This would be expected to reduce the density of the composite and its theoretical value.

X-ray transmission $\left(I / I_{o}\right)^{26}$ through the 3D printed CAs were calculated and compared to that of a standard $2 \mathrm{~mm}$ tungsten CA (see Fig.10). The attenuating material for both 3D printed CAs were $2 \mathrm{~mm}$ thick with a $0.5 \mathrm{~mm}$ thick base of the mould. First the mass attenuation coefficient $(\mu / \rho)$ (see Eq.8) for a compound was found, where $w_{i}$ is the fraction by weight of each individual element and $i$ representing individual elements . Once $\mu / \rho$ was determined, $I / I_{o}$ was calculated using Eq.9, where $I_{o}$ is the incident photon, $I$ is the emerged photon along with the mass thickness $x$.

$$
\mu / \rho=\sum_{i} w_{i}(\mu / \rho)_{i}
$$


(a)

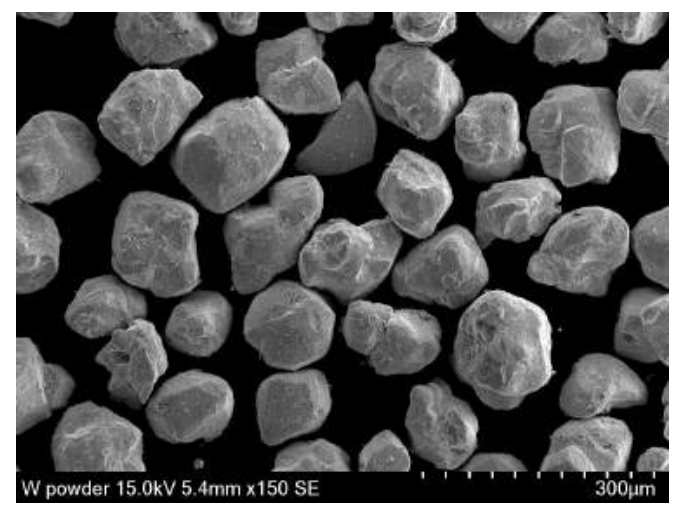

(c)

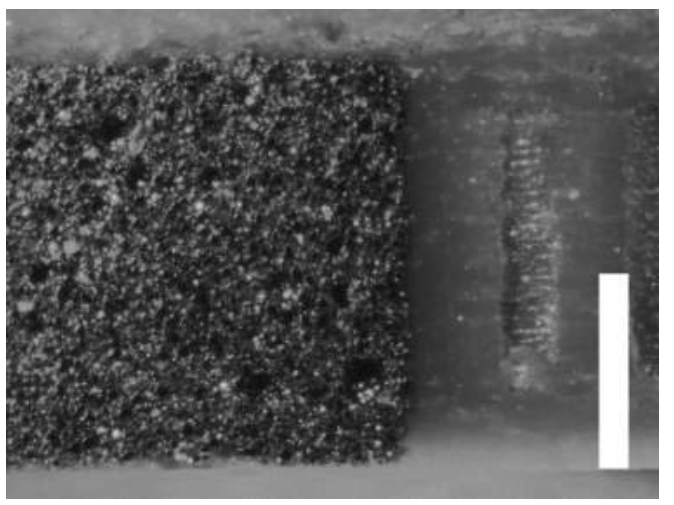

(b)

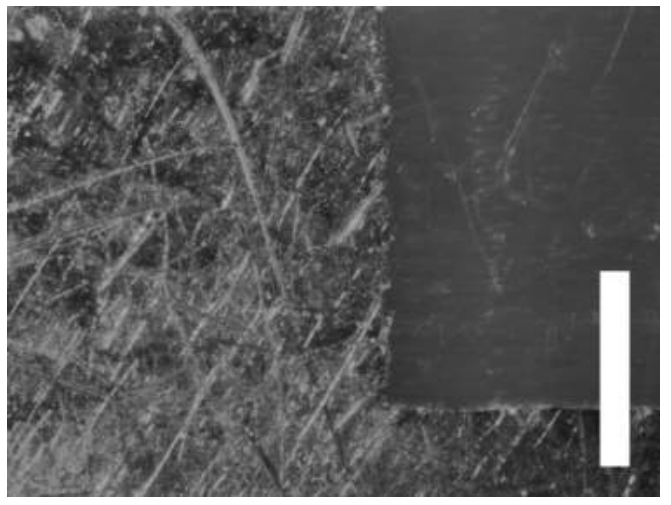

(d)

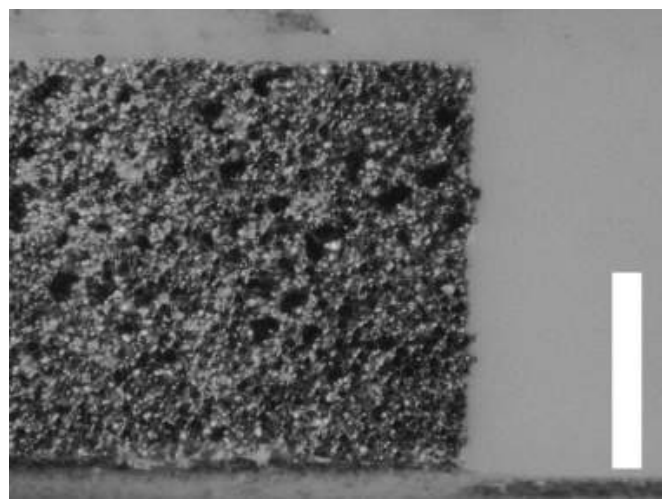

Figure 9: (a) SEM of tungsten powder sample. (b) Hot cast sample. (c) Air pockets presnt in the Technon ${ }^{\circledR}$ mixture at $9.6 \mathrm{~g} \mathrm{~cm}^{-3}$ and (d) $10.6 \mathrm{~g} \mathrm{~cm}^{-3}$ (bar lenth $1 \mathrm{~mm}$ ).

$$
I / I_{o}=e^{-(\mu / \rho) x}
$$

X-ray fluorescence (XRF) was performed on the bismuth alloy with an SII Nanotechnology Inc SEA6000VX HS Finder $\mathrm{R}^{27}$ to confirm its composition by concentration. The procedure included XRF at six randomly selected locations of the sample and an average value was found. The results were (Bi $57 \pm 3$, Sn $26 \pm 2$ and In $117 \pm 3) \mathrm{wt} \%$, where the uncertainty is the standard deviation.

\section{DISCUSSION}

Two methods of hot and cold casting were used to fabricate 3D printed CAs. Constructed CAs using the hot cast method proved more difficult and less reliable than cold casting. Numerous failed attempts were made before a suitable CA was constructed. Smaller metallic elements of the CA were prone to loosening, which rendered the overall structure rather unstable (see Fig.3). Therefore, only results from the cold cast process and tungsten alloy NTHT CAs were presented.

A higher tungsten concentration in the Technon ${ }^{\circledR}$ mixture increased its density. The density of samples with varying tungsten concentration were confirmed using a pycnometer. Results showed that the measured density deviated from its calculated value when the concentration of tungsten in the mixture was above 


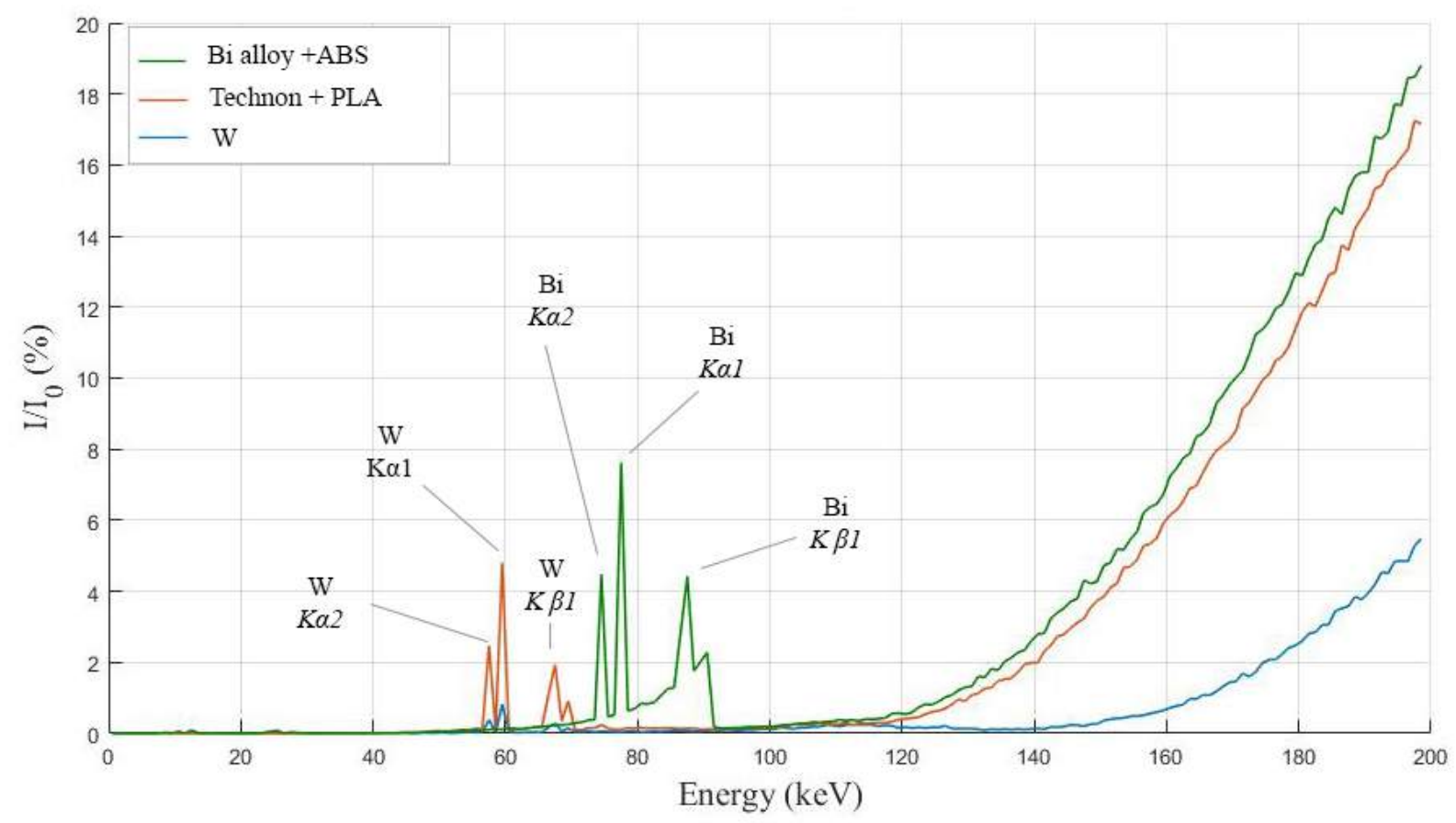

Figure 10: X-ray transmission for each $2 \mathrm{~mm}$ thick attenuating material.

94.6\%. Tungsten powder used in Technon ${ }^{\circledR}$ mixture was analysed in a SEM, which was revealed as somewhat angular and on average reported to be consistent with the manufacturers stated maximum size of 149 $\mu \mathrm{m}$. Sampled section of each hot and cold CAs were extracted to investigate the fill within its mould. What was found, was the mixture/alloy taking shape of its mould during the casting process, revealing a perfect fill with no cavity or gaps. However, it was notable that air pockets were present in the cured Technon ${ }^{\circledR}$ mixture in Fig.9. This was more common at higher tungsten concentrations, which may explain inconsistency in densities with a greater concentration of $94.6 \%$ for tungsten. Consequently, using 93.5-94.6\% tungsten was more of a stable option in terms of obtaining a density value close to its calculated figure.

A sample of bismuth alloy was accessed using XRF. The concentration of each element in the alloy was close to its calculated value and was affirmed with its confirmed density. Overall, the results deviated by $0.1 \mathrm{~g}$ $\mathrm{cm}^{-3}$, which can be considered to be rather small. X-ray transmission was calculated for $2 \mathrm{~mm}$ thick bismuth

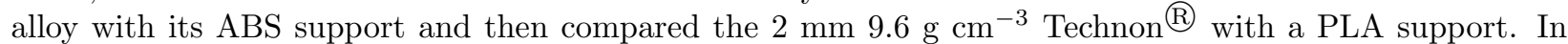
addition, $2 \mathrm{~mm}$ thick tungsten was added to the comparison which had significantly less transmission, as a result of being approximately twice the density of the 3D printed CAs. As expected, the cold cast CA out performed the hot cast $\mathrm{CA}$. The cold cast $\mathrm{CA}$ contained less than $1 \% \mathrm{X}$-ray transmission at $100 \mathrm{kV}$; which was the voltage used in the X-ray backscatter experiments in this paper (Fig.10).

The PSF of each theoretical mask was calculated and compared to ${ }^{241}$ Am source exposures. Consequently, this acts as a calibrator for the image decoding process. Thus, if the ${ }^{241} \mathrm{Am}$ source image is similar to the calculated PSF using the same mask, then the integrity of reconstructed X-ray backscatter images are upheld. It is important to note, that the ${ }^{241} \mathrm{Am}$ was not a true point source and had a toroid shape for its container. As a result, the signal in the reconstructed radioactive source images appear somewhat larger than the theoretically calculated PSF. Also, low activity of the source meant it had to be located closer to the camera than the X-ray backscatter object. The X-ray backscatter object was placed further back in order for the scene to fit within the imaging systems FOV. A direct comparison with both the object and source having the same distance to the aperture and similar aperture to detector distance would have meant undertaking 
the whole experiment again. Another important factor to consider and not shown, is that in Fig.6a and d the images were cropped out and the decoding array was padded with a mosaic for the correlation process. Ultimately, it was critical that the images or array and decoding array unit pattern size were the same for the cross correlation process to take place.

The unit pattern size in all experimental CA exposures determined the detected area and overall image size. This could be scaled to the boundary of the detector's iCCD, however, the results (particularly FWHM) would not remain comparable due to the different scaling factors that would be required. Both results from the FWHM and SNR for the 3D printed CA were superior to the tungsten alloy NTHT version. This is also justified for the FWHM, which measures the CAs imaging resolvability and can be seen in Fig.7 and 8 , where sharper images are presented using the 3D printed CA. However, such results may vary with different CA patterns and 3D printed quality of its mould. On the other hand, the quadrants cylinder in Fig.7 appear more square than circular. It is not clear why the object in the scene was not truly represented and its mis-representation may have been introduced in the image reconstruction process. Also, as the SNR was calculated from signals in the image that were cropped by eye. Therefore, a degree of uncertainty would be introduced into the final results. In addition, Compton scatter may be introduced into the image from light elements that make up the 3D printed polymer CA mould. The image quality would be decreased by the introduction of such noise. Further investigation into X-ray scatter from various print material would help determine the optimum print filament that would produced the least amount of scatter.

\section{CONCLUSION}

3D printed CAs can be considered as alternative masks for X-ray backscatter imaging. Of those examined, cold casting 3D printed CAs proved to be more cost effective and structurally stable than hot casting . Cold cast CAs also possessed higher densities, better X-ray attenuation properties and in our experience were easier to make. Using the lower concentration of tungsten in the cold cast mixture proved to be more of a reliable option, in terms of obtaining densities close to the calculated figure. Results from SNR were superior for the 3D printed CA when compared to the tungsten alloy NTHT version. The same was true for the FWHM and can be seen within the experimental images, which where slightly sharper. Conversely, the quadrants cylinder in Fig.7 appeared more square than circular, which may have been introduced in the image reconstruction process. Overall, results from the experiment revealed that images taken with a 3D printed cold cast 19 MURA were superior to those from its tungsten alloy NTHT counterpart. Nonetheless, the difference in results were small and may differ for different array patterns and 3D print quality of the mould. Future works would include investigating scatter from atomic elements that comprise the 3D printed CA mould and to solve the problem of why images were not entirely represented correctly.

\section{ACKNOWLEDGEMENTS}

The authors would like to thank Dstl for the financial support for this work.

\section{REFERENCES}

[1] Mertz, L. and Young, N. O., "Fresnel Transformation of Images," in [Optical Instruments and Techniques (Chapman and Hall Ltd)], 305-310 (1961).

[2] Dicke, R. H., "Scatter-Hole Cameras for X-Rays and Gamma Rays," Astrophysical Journal 153, L101 (1968).

[3] Accorsi, R., Design of Near-Field Coded Aperture Cameras for High-Resolution Medical and Industrial Gamma-Ray Imaging, PhD thesis (2001).

[4] Accorsi, R., Gasparini, F., and Lanza, R., "Optimal Coded Aperture Patterns for Improved SNR in Nuclear Medicine Imaging," Elsevier 474, 273-284 (2001).

[5] Faust, A., Rothschild, R., Leblanc, P., and McFee, J., "Detection of Explosive Devices using X-ray Backscatter Radiation," SPIE Vol. 4768 56(1), 299-307 (2009). 
[6] Fenimore, E. E., "Coded Aperture Imaging with Uniformly Redundant Arrays," Applied optics 17(3), $337-347$ (1978).

[7] Fenimore, E. E. and Cannon, T. M., "Uniformly redundant arrays: digital reconstruction methods.," Applied optics 20(10), 1858-64 (1981).

[8] Miller, B. W., Moore, J. W., Barrett, H. H., Fry, T., Adler, S., Sery, J., and Furenlid, L. R., "3D printing in X-ray and gamma-ray imaging: A novel method for fabricating high-density imaging apertures," Nuclear Instruments and Methods in Physics Research, Section A: Accelerators, Spectrometers, Detectors and Associated Equipment 659(1), 262-268 (2011).

[9] Fenimore, E. E. and Gottesman, S., "New Family of Binary Arrays for Coded Aperture Imaging," Applied optics 28(20), 4344-4352 (1989).

[10] VJT, "VJ Technology." Available from: http://www.vjt.com/(Accessed 25 June 2017) (2017).

[11] Photonic Science, "Gemstar X-ray Camera." Available from: http://www.photonicscience.co.uk/(Accessed 25 June 2017) (2017).

[12] Wolfmet, "Tungsten Alloys Technical Information." Available from: http://static.mimaterials.com/wolfmet/documents (Accessed 17 November 2016) (2016).

[13] Jupp, I., The Optimisation of Discrete Pixel Coded Aperture Telescopes, PhD thesis, University of Southampton (1996).

[14] Caroli, E., J., S., Di Cocco, G., Natalucci, L., and Spzzichino, A., "Coded Aperture Imaging in X - and Gamma Ray Astronomy," Kluwer Academic Publishers 45, 349-403 (1987).

[15] Dassault Systemes, "Solidworks." Available from: http://www.solidworks.co.uk/, (Accessed 28 January 2016) (2015).

[16] Ultimaker, "CURA." Available from: https://ultimaker.com/en/products/cura-software, (Accessed 8 February 2016) (2015).

[17] Ultimaker, "Ultimaker 2 Extended." Available from: https://ultimaker.com (Accessed 29 January 2016) (2015).

[18] DuPoint, "Kapton Polyimide Film." http://www.dupont.com/products-and-services/membranesfilms/polyimide-films/brands/kapton-polyimide-film.html/ (Accessed 23 June 2017) (2017).

[19] Inc, T. H. P., [Technon / Poly Kit], Available from: http://www.thpap.com/(Accessed 9 February 2016) (2001).

[20] MathWorks, "MATLAB." Available from: http://uk.mathworks.com/products/matlab/, (Accessed 24 January 2016) (2015).

[21] Lewis, J. P., "Fast Normalized Cross-Correlation," Canadian Image Processing and Pattern Recognition Society 10(11), 120-123 (1995).

[22] DeWeert, M. J. and Farm, B. P., "Lensless coded aperture imaging with separable doubly Toeplitz masks," Proceedings of SPIE - The International Society for Optical Engineering 9109, 91090Q (2014).

[23] Rasband, W., "ImageJ." Available from: http://imagej.nih.gov/ij/. (Accessed 23 February 2016) (2011).

[24] Micromeritics, "Accupyc 1330 pycnometer." Available from: http://www.micromeritics.com/(Accessed 25 June 2017) (1996).

[25] HITACHI, "SU5000 SEM." Available from: http://www.hitachi-hightech.com/(Accessed 25 June 2017) (2001).

[26] Hubbell, J. H. and Seltzer, S. M., [X-Ray Mass Attenuation Coefficients], Available from: http://www.nist.gov/pml/data/xraycoef/ (Accessed 18 February 2016) (1989).

[27] SII Nanotechnology Inc, "SEA6000VX HS Finder R." Available from: http://www.sii.co.jp/(Accessed 25 June 2017) (2017).

Content includes material subject to (c) Crown copyright (2017), Dstl. This material is licensed under the terms of the Open Government Licence except where otherwise stated. To view this licence, visit http://www nationalarchives.gov.uk/doc/open-government-licence/version/3 or write to the Information Policy Team, The National Archives, Kew, London TW9 4DU, or email: psi@nationalarchives.gsi.gov.uk. 